\title{
Unpacking Quality Assurance Issues in Distance Education, Using the University of South Africa, a Mega Open Distance Learning University as an Example
}

\author{
Lindiwe Mabuza
}

\begin{abstract}
This paper seeks to present an overview of Quality Assurance (QA) issues, trends and challenges in higher education. To assist with this task, various issues pertaining to quality assurance experienced at the University of South Africa (Unisa) will be used to illustrate some of the issues raised where deemed appropriate. Emphasis is on issues that are relevant to the management of quality in relation to student support at Unisa. The paper intends to not only demonstrate a case for a need for QA management in higher education but to also identify possible areas where improvements can be made to the way QA systems are being managed in Higher Education.
\end{abstract}

Index Terms-Higher education, management of quality, quality assurance, quality of service, student support.

\section{INTRODUCTION}

The landscape of higher education has seen many changes over the past fifteen to twenty years. Harvey and Williams [1] state that the past fifteen years in higher education have been years of "...immense change and development in higher education, all arguably connected with quality" Prior to elaborating on these changes it is an opportune moment to attempt to unpack what the term quality assurance means. Quality assurance has been described in many ways depending on stakeholder positioning. Inglis [2] describes quality assurance as seeking to guarantee that the quality of a service or product meets some predetermined standard. It has also been described as a 'multi-dimensional issue' and has a variety of meanings, which for some stakeholders portends 'excellence' and 'exceptionality', while for others it connotes 'value for money' and other such terms Krause [3]. For Watty [4], quality broadly refers to the "experience of students in their educational backgrounds". Quality is said to be both context specific and stakeholder specific. Harvey and Williams [1] also state aptly that "...quality has so many facets and different perspectives." Stakeholders in higher education are listed to include: government, QA agencies, universities and individual academics. It is however, intriguing that students are not identified as stakeholders, this I deem to be an erroneous omission as students have become an essential role player in quality assurance in higher education. The broad list of stakeholders is said to engage in the quality discourses at different times and for different reasons, Krause [3].

Manuscript received September 20, 2013; revised January 15, 2014. This work was supported in part by the National Research Foundation (South Africa) (NRF)

Lindiwe Mabuza is with the University of South Africa (Unisa) P O Box: 392, Unisa 0003, South Africa (e-mail: mabuzlok@ubnisa.ac.za).
As is shown, the term is mired in controversy in the context of higher education and as indicated previously, the problem is compounded by the many stakeholders who each have a say in it.

Quality assurance has had its proponents and opponents. There are those who see it positively - largely said to be university administrators and those who view it as an onerous, time consuming process as will be outlined. Against this background, others argue that there is a need for a new definition of quality to explain recent qualities in higher education-Harvey and Williams [1].

Having provided an introduction to QA and related issues, the next section first briefly describes the objectives of QA and elaborates on the management of quality in the trending HE environment. As mentioned earlier, Unisa will be mentioned where deemed appropriate.

\section{OBJECTIVES AND ARRANGEMENTS OF QA}

There are also various objectives for pursuing QA activities in institutions. According to Jung [5] these include: self-improvement and accountability to society in general and to the relevant QA authorities nationally. In the UK QA results are required to obtain public funding and ancillary surveys results are used to improve quality and distance teaching and learning at most universities.

Q management takes many forms; Jung [5] cites the following three:

- A centralised QA structure/centralised quality management system to coordinate and oversee implementation of QA activities using policies and guidelines formulated by committees / boards;

- A collective QA structure run by boards, councils and/or committees, and;

- A dispersed structure where QA is part of the responsibilities of one or more related administrative office.

These forms of QA are not exhaustive and it is possible that an institution may have overlaps. QA arrangements in South Africa and the University of South Africa, specifically my college are described below:

The Quality Assurance (QA) Structure in South Africa, Unisa \& the College of Economic and Management Sciences (CEMS)

In South Africa, QA is governed under the auspices of the Higher Education Quality Committee (HEQC) which is a sub-committee of the Council of Higher Education (CHE). The HEQC was established by the Higher Education Act of 
1997 and is responsible for QA in South Africa's higher education institutions. The functions of the HEQC include: promoting quality in $\mathrm{HE}$; auditing quality assurance mechanisms of HEIs and accrediting programmes of HE, CHE [6].

The portfolio of Quality Assurance at Unisa reports directly to the Vice-Principal: Institutional Development, who also chairs the institutional body that oversees QA, namely the Professional, Administrative and Academic Quality Assurance Committee (PAAQAC). Additionally, College QA Committees report to this body which is administrated by the Department: Strategy, Planning and Quality Assurance. There are various other Unisa fora where QA matters are addressed including: Senate Teaching and Learning Committee; Study Material forum meetings; QA Chairs' forum and several others. Broadly, the College QA Committee (QAC) interacts with all academic matters and activities relating to the internal quality management within the College of Economic and Management Sciences. Recently the status of the College Quality Assurance Committee has been elevated as QA is increasingly seen to be an overarching function. Instead of reporting to the College Tuition Committee it now reports to the Executive Dean of the College, and will submit regular reports to the College Executive Committee and the university's PAAQAC. The College QAC also holds monthly meetings and offers guidance on the management of quality in the College which involves several activities and tasks. It plays a pivotal role at college level including: developing QA guidelines for the college; commissioning surveys amongst students and staff and interpreting results and implementing any necessary changes - confirming the pre-eminence of QA in the institution. The following section highlights selected issues that have a bearing on QA as experienced by Unisa.

\section{Challenges}

Unisa faces a plethora of issues when it comes to the management of quality. These are both driven by external and internal factors as will be demonstrated. To set the scene, Unisa has in excess of 320,000 students, which represents a decline from 2012 where there were over 350,000 students. The College of Economic Management Sciences leads in terms of student numbers at 116,968 students in 2013. The majority of our students fall within the 20 - 29 age range, followed by the 30 - 39 age range at 110,792 and thirdly the 40 - 49 age range at 47,292 [7]. Unisa is South Africa's oldest university (turning 140 years old in 2013) and has the longest history in the provision of distance education in the world. It is the largest university on the continent and is one of the world's mega universities, enrolling more than a third of all of South African students [8].

The university is aware of a need to evolve with the world and is continually positioning itself to be a $21^{\text {st }}$ Century world university. This includes: improving its Information and Communication Technologies engaging in multi and trans-disciplinary research, forging collaborations across the globe and creating courses that can be used as Open Educational Resources (OERs) and implement online learning. Unisa's vision is captured succinctly as "Towards the African University in the service of humanity"-befitting of the role it plays in education in Africa (and beyond). Amongst its 7 goals is: "Grow Unisa as a leading ODL institution" which confirms further Unisa's intention to continue to be a leader in ODL provisioning, not only within South Africa, but in the region. As can be seen with this brief introduction, firstly Unisa has had to evolve with the trends and demands arising out of both the external and internal environments. The big question is what has this meant for QA practice in the institution? Selected issues in response to this question will be discussed hereafter.

It is important to be mindful of the fact that the Department of Basic Education in South Africa faces many challenges including that of its preparation (lack thereof) of matriculants who join institutions of HE. For many years Unisa has offered hope for those students who were not accepted by other universities in South Africa. This has compounded challenges for QA as will be demonstrated. Unisa has not only contended with high student enrolment numbers but has constantly had to deal with high failure rates / low throughput rates. It is not uncommon at Unisa for students to repeat courses for several years. The high student numbers have ripple effects on planning and capacity at the University. Known impacts include: pressure on the ICT systems or myUnisa which is a platform used by Unisa as a virtual learning environment which often experiences failure during assignment submission or peak times. Unisa is now compelled to consider alternatives such as utilising non-venue based assessment which is likely to further impact on already several QA issues. Unisa's Admission Policy was amended in 2011. Under this policy, all students who meet the basic statutory requirements are granted admission/access into Unisa for undergraduate diplomas and bachelor's degrees, thus the growing student numbers.

Additionally, alternative pathways or opportunities are provided to those not meeting the basic entry requirements, which although noble, may have contributed to the high numbers of students who eventually battle to exit the system. The College of Economic and Management Sciences has also made some attempts to provide access and foundation courses to those students who do not fully meet entry requirements. Our students mostly battle with communicating in English and mathematical application skills, often dropping out of certain courses such as quantitative methods. Some of our students also lack computer skills.

The profile of students at Unisa has changed over the years. Like the rest of the world, South Africa is also confronted with high youth unemployment and poor employability. Many measures have been put in place to try and get students to succeed. Final year students that need only the last one or two modules to graduate are, for example, placed on list of concession students who receive an additional examination opportunity coupled with special attention (where practical) to prepare them for final assessment. Whilst some students eventually succeed the majority seems to fail continuously. Various attempts have also been made to establish the reasons for lack of success amongst our students. These have included student surveys undertaken to for example, establish why students do not write exams even when granted access to 
these. It may just be added that students do not normally respond well to these surveys.

Unisa is also grappling with the fundamental question pertaining to what kind of student support to offer to our students going foward. It was stated earlier that our students are so dissimilar, how do we cater for difference in a country where questions about race and fairness are always so pervasive? How do we support one kind of student without risking the exclusion of other students in the process? We saw earlier the various age ranges with different uptake, exposure and aptitude towards technology, how would we close the gaps? These questions remain inadequately addressed. Unisa's policies and standpoints can be contradictory, a source of frustration for staff who must implement the decisions taken by executive management. Unisa for example, recently cancelled support in the form of discussion classes opting for e-tutors and face-to-face tutors only where modules were classified as high risk modules (or modules with high failure rates). Considering that some of our students in the poorer regions and rural areas and are toften the offspring of unemployed / they are unemployed themselves, and often lack access to connectivity, how are they to benefit amidst a well known digital divide in South Africa? With pressure mounting to implement online delivery, bandwidth and connectivity is an issue of concern-how do we forge ahead with a digital future when some of our students lack access to the internet? Additionally, on a separate note, where access is available, QA systems are challenged in that we have no control over what students do in the proliferation of social media, and so on. This poses a threat to the quality of teaching.

There are also issues peculiar to academics. The university is now talking about a new organisational architecture and fully going into online delivery in the future. An issue that is not often addressed is academic staff readiness for such a future. Wiesenberg and Stacey [9] cite firstly: provision of quality professional development often neglected but critical; quality learning support and quality of administrative support all of which are critical. Other than technology use, the current online environment is affected by problems at Unisa, it is often slow and capacity to receive information is very limited (at 450 megabytes). Wiesenberg and Stacey [9] raise a point of not managing change properly in HEIs which resonates with my experience at Unisa.

Other factors that militate against QA are not necessarily in our control. These include: services rendered by other Departments outside of Teaching \& Learning, for example the department dealing with the production and distribution of study material, often via courier to students not only in South Africa but also in other African countries and beyond. In 2012, Unisa was in the media for the wrong reasons calling into question the integrity of our examinations following a leak of some of our examination papers. This has necessitated changes to the procedures for handling examination papers. External issues also pose QA challenges for Unisa. Unisa's name is often wrongfully used by smaller role players purporting to be linked to Unisa. Recently an organization with a website viz. 'Togetherwepass' was found to be using Unisa's name to market its services while claiming to be associated with the institution. This is not helped by the growth in 'fly by night' colleges that are mushrooming purporting to teach Unisa courses. A question has to be asked: What is the impact of these on the quality of our qualifications?

The postal strike in the first few months of 2013 and resultant impacts on Unisa processes and subsequent provision of a quality service to students is yet another issue that militates against Unisa's quality management. These impacts include: students not receiving study material in time to begin their studies and stick to the intended schedule; work through their assignments; receive timely feedback on assignments; and prepare for exams in time: all of these affect the preparation for exams where assignments are received much too late to be of any value to preparing for exams, let alone the backlogs in the system and the turnaround times imposed by such delays in the system. Clearly quality is compromised under these circumstances. The students ultimately do not get quality service from the institution although such events are beyond the control of the university. In 2012 as well as in the first quarter of 2013 there was a national strike resulted in slow progress to get study material to students. This has repercussions on the quality of teaching and assessment, sometimes of grave proportions and it just means that not enough time is left to engage with study material and little or no feedback to students who must also sit for exams. Additionally, numerous staff in the institution participate in industrial action on an annual basis in the first quarter of the year to negotiate a better salary increase. In mid April 2013, the university's operations were paralysed by strike action for four days!

From this section it is shown that Unisa faces many issues which we need to manage and resolve in order to maintain quality of service delivery to students. The next section summarizes and concludes the salient points in this paper and makes recommendations to improve the status quo.

\section{CONCLUSION}

This paper has provided a discussion on QA and noted several trends, issues and challenges affecting higher education and QA, with emphasis on distance education, using Unisa as an example. An attempt was made to describe and discuss some of these in a distance education environment using the example of Unisa. I would argue strongly that QA is essential in Higher Education and that it is of particular importance in Distance Education. QA processes for different forms of HE provision are required. The definition of QA in section 1 proved to be highly subjective and not devoid of debate. Emerging trends such as technological advances challenge existing QA frameworks. QA has been criticised for its failure to deal with trans-national / cross border education as well as its inability to control and/or deal with 'fly by night' profiteering. QA is argued to be lacking in suitable benchmarks, which are important to foster healthy competition; establish suitable standards and protect the interests of students. This leads to complexity when dealing with rankings on a global scale.

Increasingly students want assurance that they are enrolling in institutions of good academic standing, without QA there would be no way of distinguishing between 
institutions. There is no doubt that QA has a predominant place in higher education. The key issues emanating from the discussions in this essay include: Trends in higher education have propelled a new trajectory for QA in terms of pedagogy and delivery; there is no one solution fits all; DE for example warrants a different approach from traditional universities and QA has led to benefits and challenges simultaneously. QA needs a holistic and integrated approach - from administration, academics, systems and infrastructure as was shown in the earlier sections ([10]).

In light of the observed shortcomings potential areas of improvement include: attention that must be paid to develop specific QA mechanisms for DE, for example, more research may need to be done to investigate this further; the need for attainment of suitable, reliable benchmarks to improve assessment; appropriate national regulatory frameworks taking into account the smaller education service providers may be required to mitigate against profiteering. Institutions also need to be realistic when responding to changes in the external environment. Going fully online amidst the cited challenges such as the preparedness of staff and students and in Unisa's case would be erroneous and not be assistive to student support.

\section{ACKNOWLEDGMENT}

The author would like to acknowledge the National Research Foundation (NRF) for providing the travel grant to enable presentation of this paper at ICEPS 2014 in Barcelona, Spain as well as the University of South Africa for supplemental funding and affording her such an opportunity to be counted among international scholars!

\section{REFERENCES}

[1] L Harvey and J Williams, "Fifteen years of quality in higher education," Quality in Higher Education, vol. 16, no. 1, pp. 3-36, 2010.
[2] A Inglis, "Quality improvement, quality assurance, and benchmarking: Comparing two frameworks for managing quality processes in Open and Distance Learning," The International Review of Research in Open and Distance Learning, vol. 6, no. 1, pp. 1-8, 2005.

[3] K. Krause, Higher Education Research \& Development Addressing the wicked problem of quality in higher education: theoretical approaches and implications, pp. 37-41, 2012.

[4] K. Watty, "When will academics learn about quality?" Quality in Higher Education, vol. 9, no. 3, pp. 213-221, 2003.

[5] I. Jung. (2004). Quality assurance survey of mega universities. [Online]. chapter $7 . \quad$ Available: http://citeseerx.ist.psu.edu/viewdoc/download?doi=10.1.1.180.7945\& rep=rep $1 \&$ type $=$ pdf

[6] Council for Higher Education. (2005). The work of the HEQC. [Online]. chapter $3 . \quad$ Available: http://www.che.ac.za/documents/d000126/7-CHE_Annual_Report_05 -06.pdf

[7] Unisa, Department of Institutional Statistics and Analysis. (2013). Unisa headcount for the university and college of economic and management services. (2009-2011). [Online]. Available: http://heda.unisa.ac.za

[8] Unisa Annual Report. (2011). [Online]. Available http://www.unisa.ac.za/happening/docs/AnnualReport_2011.pdf

[9] F. P. Wiesenberg and E. Stacey, "Reflection on teaching and learning online: Quality program design, delivery and support issues from a cross-global perspective," Distance Education, vol. 26, no. 3, pp. 385-404, 2005.

[10] G. Scott, "Assuring quality and effective change management in international higher education," Address NAFSA Conference Baltimore, April 2004.

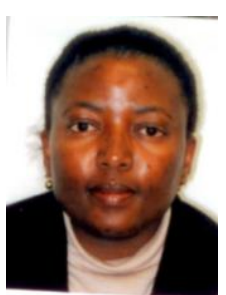

Lindiwe Mabuza currently registered for EdD (Higher Education) at Sheffield University, UK. She is the coordinator: Tuition and Quality Assurance at College of Economic and Management Sciences in the University of South Africa.

Lindiwe holds a master in environment and development from the University of KwaZulu Natal, South Africa in 1998. 